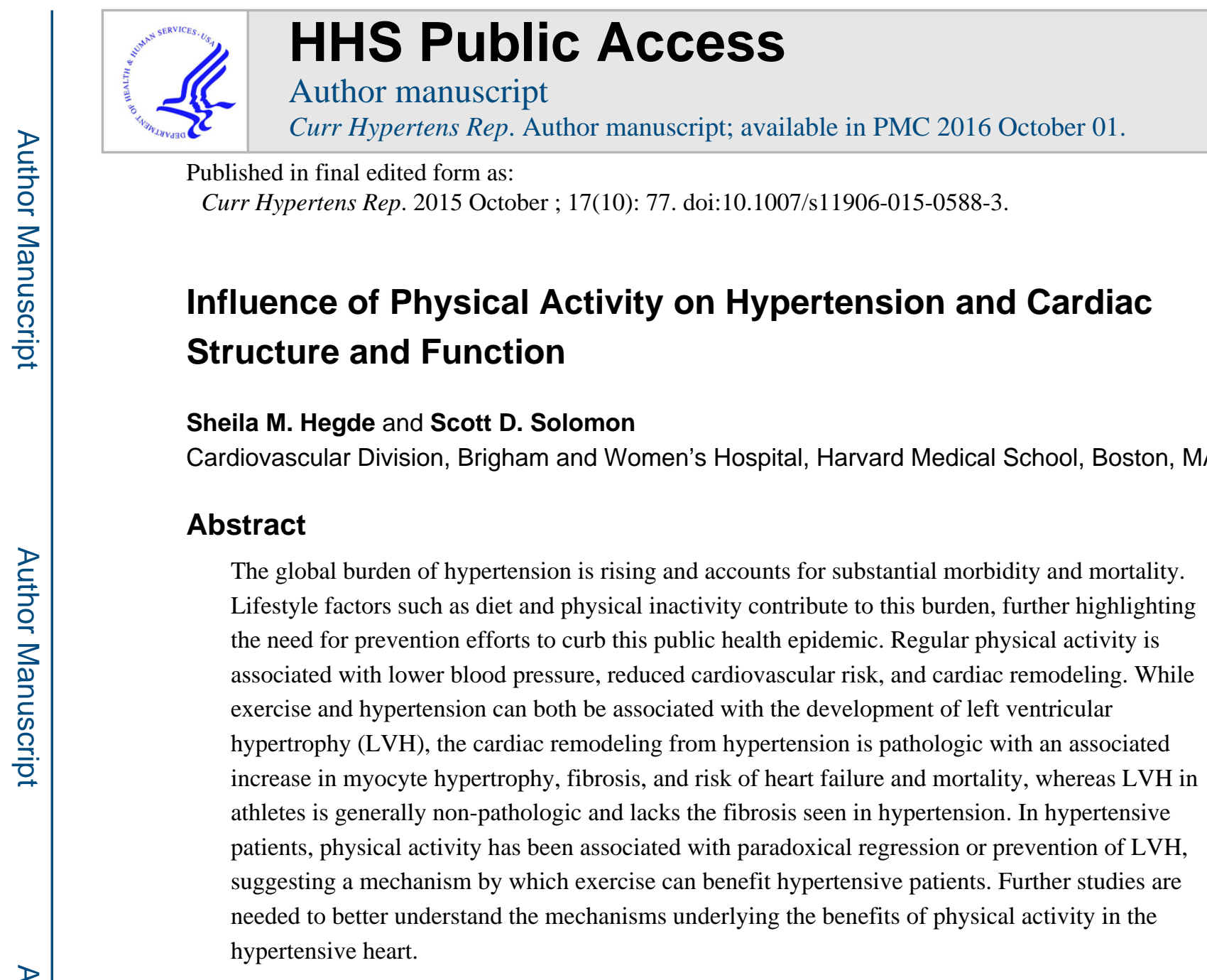

Keywords

Physical activity; hypertension; cardiac remodeling

\title{
Introduction
}

Globally, hypertension is the leading risk factor for morbidity and mortality, causing an estimated 9.4 million deaths in 2010 [1]. Several end organ effects, particularly compensatory increases in left ventricular (LV) wall thickness and mass, are characteristic features of the hypertensive heart that act as an independent predictor of adverse cardiovascular events. Fortunately, treatment of hypertension can prevent progression or development of LV hypertrophy $(\mathrm{LVH})$ and reduce cardiovascular risk [2-5].

Lifestyle factors, including physical inactivity, are important modifiable risk factors in the development of hypertension. In addition to standard anti-hypertensive therapy, the benefits of physical activity on hypertension and cardiovascular disease have been well demonstrated [6-9]. Accordingly, physical activity and other lifestyle modifications are an important component of American, European, and World Health Organization guidelines for anti-

Address correspondence to: Scott D. Solomon, MD, Cardiovascular Division, Brigham and Women's Hospital, 75 Francis St, Boston, MA 02115, ssolomon@ rics.bwh.harvard.edu. 
hypertensive therapy [10-12]. Although the effect of physical activity on hypertension and on the heart have each been well described, the mechanisms underlying the protective effect of physical activity on the hypertensive heart are not well understood. Here, we review the most recent evidence for the influence of physical activity on hypertension and cardiac structure and function.

\section{Physical Activity and Hypertension}

Exercise is a key component of lifestyle therapy for the primary prevention and treatment of hypertension. A number of studies consistently demonstrate beneficial effects of exercise on hypertension with reductions in both systolic and diastolic blood pressure with as much as $5-7 \mathrm{mmHg}$ reductions in those with hypertension [6,13-16].

Acutely, exercise has been associated with immediate significant reductions in systolic blood pressure. This immediate reduction in blood pressure after exercise can persist for almost 24 hours and is referred to as post-exercise hypotension with the most pronounced effects seen in those with higher baseline blood pressure [13]. More frequent or chronic exercise results in more sustained reductions in blood pressure referred to as the exercise training response [17]. Although age, sex, or ethnicity do not appear to change the blood pressure response to exercise, it should be noted that most studies have been limited by primarily studying only populations of middle-aged men of European descent [18].

The reduction in blood pressure with physical activity is thought to be due to attenuation in peripheral vascular resistance, which may be due to neurohormonal and structural responses with reductions in sympathetic nerve activity and an increase in arterial lumen diameters, respectively [19]. Other proposed mechanisms for blood pressure reduction include favorable changes in oxidative stress, inflammation, endothelial function, arterial compliance, body mass, renin-angiotensin system activity, parasympathetic activity, renal function, and insulin sensitivity [6]. The mechanisms underlying blood pressure reduction with exercise and its associated outcomes are still under investigation with many studies limited by size and marked heterogeneity [20].

Furthermore, the anti-hypertensive response to exercise is highly variable; differences in exercise regimens, environmental factors, and genetic factors may be responsible for considerable inter- and intra-study variability in the blood pressure response to exercise [18]. In one study, 20-25\% of those with hypertension were non-responders with no reduction in blood pressure with exercise [21]. Studies investigating the genetic and clinical factors associated with responders and non-responders are ongoing [18].

\section{Cardiac Remodeling}

The adaptation to pressure overload states such as that with hypertension differs from that of the volume overload state associated with endurance exercise training. Both states are associated with well-described changes in cardiac structure. 


\section{Effect of Hypertension on the Heart}

Hypertension is frequently characterized by pathologic left ventricular remodeling with concentric hypertrophy. By the Laplace law, the response to hypertension is initially adaptive with increases in wall thickness to decrease wall stress and oxygen demand. However, in some cases, chronic pressure overload results in a transition to a maladaptive response with concentric hypertrophy, eventual decompensation, and clinical heart failure [22]. Preventing or limiting the hypertrophic response to hypertension may therefore be integral in preserving cardiac function and preventing progression to heart failure and other adverse cardiovascular events. Anti-hypertensive therapy has proven to be an important intervention associated with regression or normalization of LVH in some patients [23].

Although LVH is the most commonly described cardiac adaptation to hypertension, changes in diastolic function and the left atrium are also associated with hypertension. Several studies demonstrate that diastolic dysfunction and left atrial (LA) enlargement are associated with hypertension [24-28]. The chronic afterload of hypertension results in LVH accompanied by impaired LV relaxation or filling, which results in an increase in LA pressure; the resulting chronic LA stretch is thought to induce LA enlargement [29].

The hypertensive heart can also be characterized by right ventricular hypertrophy (RVH) with a prevalence of approximately $30 \%$ from a meta-analysis of subjects with systemic hypertension [30,31]. Further studies are needed to evaluate the impact of these RV changes and subsequent anti-hypertensive treatment.

\section{Effect of Physical Activity on the Heart}

Much of what is known about the effects of exercise on the heart comes from studies on endurance athletes. Cardiac remodeling among athletes varies by the type of sport and its associated hemodynamic effects on the heart, commonly known as the Morganroth hypothesis [32,33]. Endurance exercise with predominant isotonic physiology typically results in eccentric LV remodeling with chamber enlargement and wall thickening in response to the increased volume load [34]. In contrast, isometric exercise is typically characterized by concentric LV remodeling without chamber enlargement in response to the increase in systemic vascular resistance [34]. Furthermore, athletes in mixed physiology sports have shown variable forms of cardiac remodeling [35]. While usually within normal limits, LV function may also be low normal or slightly depressed in endurance athletes at rest; this is thought to reflect physiologic reserve as these athletes often demonstrate normal or super-normal exercise capacity during provocative testing [36,37].

The Morganroth hypothesis has been recently challenged. The expected cardiac adaptations of eccentric hypertrophy and increased cardiac dimensions have been reproduced in endurance athletes, however, the expected pattern of concentric hypertrophy in strengthtrained athletes has not been consistently demonstrated in recent reviews or meta-analyses $[38,39]$. The absence of cardiac remodeling may be due to the transient and intermittent exposure to pressure overload, that the expected rise in pressure may be balanced by a simultaneous Valsalva maneuver, or due to the limited number and marked heterogeneity in published studies in resistance-trained athletes. 
Recent studies have brought more attention to the RV response to exercise. In endurance training, the RV enlarges similarly to the $\mathrm{LV}$ in response to the increase in cardiac output and volume overload, suggesting the presence of a balanced response to endurance exercise $[40,41]$. RV function may also be mildly reduced at rest but as seen in the LV, this may reflect contractile reserve in the endurance athlete $[42,43]$. RV hypertrophy, however, has not been shown in response to exercise and may reflect abnormal physiology in the absence of coexisting pulmonary hypertension. The pulmonary vasculature is protected from the large rise in intravascular pressure seen in strength-trained athletes, and this may explain the absence of RV changes in response to isometric exercise [43].

The athlete's heart is also associated with LA enlargement in endurance athletes [44]. LA enlargement in athletes has been associated with normal or super-normal diastolic function [33]. While normal tissue Doppler imaging (TDI) does not exclude a pathologic condition such as hypertrophic cardiomyopathy, the presence of abnormal TDI strongly suggests a pathologic diagnosis [33]. Studies investigating changes in LA and RV structure and function are limited in resistance-trained athletes.

Furthermore, sex and racial differences have been demonstrated in the athlete's heart. In men and women matched for training history, male athletes develop more marked LVH while female athletes have greater LV dilation $[45,46]$. Black athletes also demonstrate a greater degree of LVH compared to white athletes [45,47].

The dose response of exercise does not appear to be linear. Prolonged ultra-endurance exercise has been associated with maladaptive changes, including adverse cardiac remodeling and increased fibrosis $[40,48,49]$. The absence of regression or normalization with detraining is thought to distinguish these athletes from those with physiologic adaptations.

Reducing or abstaining from exercise has been associated with regression of myocardial adaptations to exercise [50-52]. Accordingly, detraining has been prescribed to differentiate physiologic from pathologic hypertrophy [33]. A group of elite male athletes with eccentric LVH demonstrated regression of LV mass and wall thickness to normal values while resolution of LV cavity enlargement remained incomplete with residual LV dilation in $22 \%$ of the cohort [51]. Regression of LVH in strength-trained athletes with concentric hypertrophy has also been demonstrated in a small cohort of 5 athletes [53]. The time necessary for meaningful detraining remains unknown.

\section{Physical Activity and Cardiac Remodeling in the Hypertensive Heart}

The influence of physical activity on the hypertensive heart, however, is less well described with relatively few published clinical trials in humans. Exercise in the hypertensive patient may be expected to result in LVH given the physiologic and pathologic remodeling typically seen in response to exercise and hypertension, respectively; however, several focused studies have demonstrated a paradoxical response to exercise with favorable effects on LV mass and structure (Table 1) [54-59]. 
In hypertensive subjects, regular aerobic exercise over a period of 16 weeks in 40 subjects was associated with significant reductions in LV mass index compared to controls whose LV mass did not change over the course of the study [59]. Active subjects also demonstrated significant reductions in systolic and diastolic blood pressure at baseline and at all stages of exercise as well as an improvement in functional capacity.

In a larger cohort of 454 people (ages 18-45) with stage I hypertension, those with regular physical activity had a lower risk of developing LVH compared to sedentary subjects (crude $\mathrm{OR}=0.15, \mathrm{CI}, 0.05-0.52$ ) with a slight decrease in association after controlling for age, sex, family history of hypertension, hypertension duration, follow-up length, smoking status, alcohol and caffeine intake, and baseline blood pressure, BMI, and LV mass (adjusted $\mathrm{OR}=0.24, \mathrm{CI}, 0.07-0.85$ ) [58]. Findings remained unchanged after adjusting for blood pressure and weight changes during follow-up [58]. Furthermore, sedentary participants were more likely to demonstrate an increased LV mass index and wall thickness compared to their active counterparts.

Older hypertensive patients aged 55-80 years also demonstrated a lower LV mass index in those that were physically active compared to those who were sedentary in 958 participants in the LIFE echocardiographic substudy in which subjects had yearly echocardiograms over 3 years of medical therapy $[57,60]$. This favorable association with lower LV mass in the active group remained after adjustment for BMI and sex. Lower LV mass was also associated with improved cardiovascular outcomes of mortality and stroke over 4.8 years. The reduction in adverse cardiovascular outcomes in the active group was independent of LV mass, suggesting that the benefits of activity and lower LV mass on outcomes are independent [60]. Activity level requirements were modest; the active group participated in greater than 30 minutes of activity twice a week. There was no significant difference in LV dimensions or ejection fraction between activity groups.

At odds with these findings, others have demonstrated no significant change in LV mass or structure with exercise [61]. No change in LV structure or function was seen with activity in a cohort of 23 subjects with heterogeneity in the prevalence of hypertension [62]. In another small cohort of 15 subjects with controlled hypertension, supervised exercise training was associated with improvements in improved physical capacity and muscle strength but no change in cardiac structure or function after 6 months of exercise [63]. Another group demonstrated a significant increase in LV mass with 10 weeks of exercise in 51 men [64]. Ultimately, the response may depend on a number of factors: type, intensity, and amount of exercise training; blood pressure response to exercise; duration of hypertension; and concomitant anti-hypertensive therapy. The response of the RV and LA has not been addressed in these few studies nor is there discussion of the effect of detraining in this population.

\section{Biochemical, Molecular, and Cellular Mechanisms}

The molecular and cellular response to exercise in the setting of hypertension has primarily been investigated in animal models, suggesting various potential mechanisms for favorable or maladaptive responses in the heart. 
Sympathetic Nervous System-The effect of exercise on the sympathetic nervous system may play an important role in cardiac remodeling in the hypertensive heart. In addition to reductions in blood pressure, regular exercise has been associated with beneficial effects on heart rate and insulin resistance, which have been attributed to decreased sympathetic activity [14]. Significant reductions in plasma norepinephrine by $29 \%$, plasma renin by $20 \%$, and systemic vascular resistance by $7.1 \%$ have been demonstrated with exercise training in a subset of a meta-analysis involving up to 18 of 105 study groups [7]. Reduced sympathetic nervous system activity, renin-angiotensin-aldosterone, and systemic vascular resistance may prevent increases in LV mass in hypertensive hearts.

Left Ventricular Hypertrophy-Hypertrophy is a complex response to various stimuli and has been characterized as physiologic or pathologic, both thought to be the results of distinct signaling pathways. Physiologic remodeling is associated with cardiomyocyte hypertrophy with normal or improved cardiac function [65]. Pathologic remodeling, however, is typically characterized by cardiomyocyte loss (apoptosis and necrosis), fibrosis, ventricular dysfunction, and increased risk of heart failure and sudden death [65].

Of the various cardiac signaling pathways, the IGF-1/IGF-1R/Akt axis is thought to play a large role in exercise-induced cardiac remodeling $[66,67]$. Physiologic hypertrophy is mediated by insulin-like growth factor-1 (IGF-1). Exercise has been associated with increased secretion of IGF-1 in the bloodstream and cardiac expression of IGF-1. IGF-1 receptor activation leads to downstream signaling of key mediators of cell growth and survival (PI3K, Akt1). Mice with over-expression of IGF-1 demonstrate cardiomyocyte hypertrophy and hyperplasia as well as prevention of aging-associated cardiomyocyte attrition, consistent with physiologic hypertrophy [66,68-70]. In humans, IGF-1 levels correlate with LV mass index and LV cavity dimensions [71]. This same pathway appears to play an important protective role in the setting of pathologic stimuli such as hypertension given that mice deficient in PI3K or Akt1 display accelerated heart failure phenotypes [7274]. In contrast, pathologic hypertrophy appears to be mediated by G protein-coupled receptors (Gaq) activated by angiotensin II and endothelin-1 [65,66,75]. Transgenic mice with inhibition of Gaq signaling do not demonstrate pressure overload-induced hypertrophy [76,77].

In hypertensive hearts, however, the mechanism of reduction in LVH with exercise is not well understood. Swimming in spontaneously hypertensive rats (SHRs) has been associated with a decrease in myocardial fibrosis, increase in myocardial capillary density, and upregulation of sarcoplasmic reticulum calcium ATPase (SERCA2a) expression with improved LV systolic function, resulting in conversion from pathologic to physiologic hypertrophy [78]. This has been further demonstrated at the cellular level by elongation of LV myocytes and an increase in cell length to width ratio [79]. This may allow the heart to better respond to the demands of a pressure-overload state [66]. Other studies in SHRs have demonstrated cardiomyocyte hypertrophy with eccentric remodeling with chronic aerobic exercise training with a relative decrease in apoptosis $[79,80]$. Further studies are needed to better understand the underlying molecular mechanisms of exercise-induced cardiac remodeling in hypertensive hearts. 
Contractility and Calcium Handling-Exercise training has also been associated with improved cardiomyocyte contractility, which has been attributed to alterations in intracellular calcium handling [81]. Improvements in calcium handling, including enhanced calcium sensitivity, contractility, and sarcoplasmic reticulum activity have been associated with exercise [82]. In hypertensive rats, exercise-training has also been associated with an increase in expression of calcium-regulatory proteins (SERCA2a, phospholamban, and ryanodine receptors) [78,83]. Exercise in hypertensive hearts may therefore improve or prevent abnormal calcium handling [79].

Cardiomyocyte Turnover-With regular, moderate endurance exercise, several animal studies have also demonstrated a decrease in age-associated apoptosis and increase in cardiac heat shock protein (HSP70) expression, which inhibits apoptosis [66]. This may, in turn, prevent the cascade of pathologic remodeling. The rate of apoptosis has also been attenuated in hypertensive rats with exercise training relative to sedentary hypertensive rats [80].

Furthermore, recent studies have verified the presence of endogenous cardiac stem and progenitor cells (eCSC) in the adult heart with exchange of up to half of an individual's cardiomyocytes during a normal lifespan [66,84]. Endurance exercise has been associated with increased proliferation and cardiogenic differentiation of eCSCs, further contributing to the physiologic response $[66,80]$.

MicroRNAs-Given the challenge of targeting a pathway with multiple actions, recent studies have focused on microRNAs (miRNAs), which are small, non-coding RNAs that regulate gene expression. The miRNAs can associate with the 3'-untranslated regions of messenger RNAs (mRNAs) with imperfect base-pairing and negatively impact gene expression by mRNA degradation or inhibition of translation [85]. Several miRNAs have been implicated in hypertension-associated cardiac remodeling, and exercise training has been associated with reversal or prevention of the pathological cascade mediated by these miRNAs. Additional studies are needed to further understand these pathways and identify potential therapeutic targets [18,85-87].

\section{Conclusions}

The physiologic and pathologic changes in cardiac structure and function in response to exercise and hypertension have been well demonstrated separately; however, our knowledge regarding the influence of physical activity on the hypertensive heart remains limited. Our current understanding comes from primarily small studies in middle-age white males with variable exercise modalities, intensity, and duration and variable control and duration of hypertension. Despite these limitations, exercise appears to have a positive effect on remodeling of the hypertensive heart with paradoxical regression or prevention of $\mathrm{LVH}$. This regression of pathologic LVH appears be independent of body mass and changes in blood pressure with exercise. Various biochemical, molecular, and cellular pathways are implicated in the cardiac response. Further studies are needed to better understand the response to exercise in the hypertensive heart and which populations may benefit. 


\section{References}

Papers of particular interest, published recently, have been highlighted as:

- Of importance

•• Of major importance

1. Campbell NRC, Lackland DT, Niebylski ML. the World Hypertension League and International Society of Hypertension Executive Committees. High Blood Pressure: Why Prevention and Control Are Urgent and Important-A 2014 Fact Sheet From the World Hypertension League and the International Society of Hypertension. J. Clin. Hypertens. 2014; 16:551-553.

2. Cuspidi C, Facchetti R, Bombelli M, Sala C, Tadic M, Grassi G, et al. Prognostic value of left ventricular mass normalized to different body size indexes: findings from the PAMELA population. J. Hypertens. 2015; 33:1082-1089. [PubMed: 25668356]

3. Pierdomenico SD, Lapenna D, Cuccurullo F. Regression of Echocardiographic Left Ventricular Hypertrophy After 2 Years of Therapy Reduces Cardiovascular Risk in Patients with Essential Hypertension. Am. J. Hypertens. 2008; 21:464-470. [PubMed: 18369364]

4. Ruilope LM, Schmieder RE. Left Ventricular Hypertrophy and Clinical Outcomes in Hypertensive Patients. Am. J. Hypertens. 2008; 21:500-508. [PubMed: 18437140]

5. Rodilla E, Pascual JM, Costa JA, Martin J, Gonzalez C, Redon J. Regression of left ventricular hypertrophy and microalbuminuria changes during antihypertensive treatment: J. Hypertens. 2013; 31:1683-1691. [PubMed: 23835910]

6. Diaz KM, Shimbo D. Physical Activity and the Prevention of Hypertension. Curr. Hypertens. Rep. 2013; 15:659-668. [PubMed: 24052212]

7. Cornelissen VA, Fagard RH. Effects of Endurance Training on Blood Pressure, Blood PressureRegulating Mechanisms, and Cardiovascular Risk Factors. Hypertension. 2005; 46:667-675. [PubMed: 16157788]

8. Leitzmann MF, Park Y, Blair A, et al. Physical activity recommendations and decreased risk of mortality. Arch. Intern. Med. 2007; 167:2453-2460. [PubMed: 18071167]

9. Rossi A, Dikareva A, Bacon SL, Daskalopoulou SS. The impact of physical activity on mortality in patients with high blood pressure: a systematic review. J. Hypertens. 2012; 30:1277-1288. [PubMed: 22573122]

10. James PA, Oparil S, Carter BL, et al. 2014 evidence-based guideline for the management of high blood pressure in adults: Report from the panel members appointed to the eighth joint national committee (jnc 8). JAMA. 2014; 311:507-520. [PubMed: 24352797]

11. Members AF, Mancia G, Fagard R, Narkiewicz K, Redon J, Zanchetti A, et al. 2013 ESH/ESC Guidelines for the management of arterial hypertension. Eur. Heart J. 2013; 34:2159-2219. [PubMed: 23771844]

12. Mendis, S. World Health Organization. Global status report on noncommunicable diseases 2014. 2014.

13. Pescatello LS, Franklin BA, Fagard R, Farquhar WB, Kelley GA, Ray CA. Exercise and Hypertension: Med. Sci. Sports Exerc. 2004; 36:533-553. [PubMed: 15076798]

14. Fagard RH. Exercise Therapy in Hypertensive Cardiovascular Disease. Prog. Cardiovasc. Dis. 2011; 53:404-411. [PubMed: 21545926]

15. Cornelissen VA, Smart NA. Exercise Training for Blood Pressure: A Systematic Review and Meta-analysis. J. Am. Heart Assoc. 2013; 2:e004473. [PubMed: 23525435] A systematic review and meta-analysis of 93 studies summarizing the effects of exercise on resting blood pressure.

16. Carlson DJ, Dieberg G, Hess NC, Millar PJ, Smart NA. Isometric Exercise Training for Blood Pressure Management: A Systematic Review and Meta-analysis. Mayo Clin. Proc. 2014; 89:327334. [PubMed: 24582191]

17. Pescatello LS. Exercise and hypertension: Recent advances in exercise prescription. Curr. Hypertens. Rep. 2005; 7:281-286. [PubMed: 16061047] 
18. Ash GI, Eicher JD, Pescatello LS. The promises and challenges of the use of genomics in the prescription of exercise for hypertension: the 2013 update. Curr. Hypertens. Rev. 2013; 9:130 147. [PubMed: 23971695]

19. Hamer M. The anti-hypertensive effects of exercise: integrating acute and chronic mechanisms. Sports Med. Auckl. NZ. 2006; 36:109-116.

20. Semlitsch T, Jeitler K, Hemkens LG, Horvath K, Nagele E, Schuermann C, et al. Increasing Physical Activity for the Treatment of Hypertension: A Systematic Review and Meta-Analysis. Sports Med. 2013; 43:1009-1023. [PubMed: 23812856] A systematic review and meta-analysis of 9 studies summarizing the impact of physical activity on treatment of hypertension.

21. Pescatello LS, Blanchard BE, Tsongalis GJ, O'Connell AA, Gordish-Dressman H, Maresh CM, et al. A comparison of the genetic and clinical profile of men that respond and do not respond to the immediate antihypertensive effects of aerobic exercise. Appl. Clin. Genet. 2008; 1:7-17. [PubMed: 23776343]

22. Burchfield JS, Xie M, Hill JA. Pathological Ventricular Remodeling Mechanisms: Part 1 of 2. Circulation. 2013; 128:388-400. [PubMed: 23877061]

23. Wachtell K, Dahlöf B, Rokkedal J, Papademetriou V, Nieminen MS, Smith G, et al. Change of left ventricular geometric pattern after 1 year of antihypertensive treatment: The Losartan Intervention For Endpoint reduction in hypertension (LIFE) study. Am. Heart J. 2002; 144:1057-1064. [PubMed: 12486431]

24. Vaziri SM, Larson MG, Lauer MS, Benjamin EJ, Levy D. Influence of Blood Pressure on Left Atrial Size The Framingham Heart Study. Hypertension. 1995; 25:1155-1160. [PubMed: 7768556]

25. Cuspidi C, Rescaldani M, Sala C. Prevalence of Echocardiographic Left-Atrial Enlargement in Hypertension: A Systematic Review of Recent Clinical Studies. Am. J. Hypertens. 2013; 26:456464. [PubMed: 23388831]

26. De Simone G. Left ventricular concentric geometry is associated with impaired relaxation in hypertension: the HyperGEN study. Eur. Heart J. 2005; 26:1039-1045. [PubMed: 15618056]

27. Cuspidi C, Meani S, Fusi V, Valerio C, Catini E, Sala C, et al. Prevalence and correlates of left atrial enlargement in essential hypertension: role of ventricular geometry and the metabolic syndrome: the Evaluation of Target Organ Damage in Hypertension study. J. Hypertens. 2005; 23:875-882. [PubMed: 15775794]

28. Wachtell K, Smith G, Gerdts E, Dahlöf B, Nieminen MS, Papademetriou V, et al. Left ventricular filling patterns in patients with systemic hypertension and left ventricular hypertrophy (the LIFE study)? Am. J. Cardiol. 2000; 85:466-472. [PubMed: 10728952]

29. Matsuda M, Matsuda Y. Mechanism of left atrial enlargement related to ventricular diastolic impairment in hypertension. Clin. Cardiol. 1996; 19:954-959. [PubMed: 8957600]

30. Cuspidi C, Sala C, Muiesan ML, De Luca N, Schillaci G. Right ventricular hypertrophy in systemic hypertension: an updated review of clinical studies. J. Hypertens. 2013; 31:858-865. [PubMed: 23449015]

31. Cuspidi C, Negri F, Giudici V, Valerio C, Meani S, Sala C, et al. Prevalence and clinical correlates of right ventricular hypertrophy in essential hypertension: J. Hypertens. 2009; 27:854-860. [PubMed: 19516183]

32. Morganroth J, Maron BJ, Henry WL, Epstein SE. Comparative Left Ventricular Dimensions in Trained Athletes. Ann. Intern. Med. 1975; 82:521-524. [PubMed: 1119766]

33. Pelliccia A, Maron MS, Maron BJ. Assessment of Left Ventricular Hypertrophy in a Trained Athlete: Differential Diagnosis of Physiologic Athlete's Heart From Pathologic Hypertrophy. Prog. Cardiovasc. Dis. 2012; 54:387-396. [PubMed: 22386289] A review detailing the spectrum of cardiac remodeling in the athlete's heart compared hypertrophic cardiomyopathy.

34. Baggish AL, Wang F, Weiner RB, Elinoff JM, Tournoux F, Boland A, et al. Training-specific changes in cardiac structure and function: a prospective and longitudinal assessment of competitive athletes. J. Appl. Physiol. 2008; 104:1121-1128. [PubMed: 18096751]

35. Weiner RB, Wang F, Isaacs SK, Malhotra R, Berkstresser B, Kim JH, et al. Blood Pressure and Left Ventricular Hypertrophy During American-Style Football Participation. Circulation. 2013; 128:524-531. [PubMed: 23897848] 
36. Baggish AL, Yared K, Weiner RB, Wang F, Demes R, Picard MH, et al. Differences in Cardiac Parameters Among Elite Rowers and Sub-elite Rowers: Med. Sci. Sports Exerc. 2009:1.

37. Lauschke J, Maisch B. Athlete's heart or hypertrophic cardiomyopathy? Clin. Res. Cardiol. 2009; 98:80-88. [PubMed: 18853091]

38. Utomi V, Oxborough D, Whyte GP, Somauroo J, Sharma S, Shave R, et al. Systematic review and meta-analysis of training mode, imaging modality and body size influences on the morphology and function of the male athlete's. Heart. 2013; 99:1727-1733. [PubMed: 23474689] A systematic review and meta-analysis of 92 studies summarizing the cardiac remodeling of the athlete's heart.

39. Naylor LH, George K, O'Driscoll G, Green DJ. The athlete's heart: a contemporary appraisal of the "Morganroth hypothesis". Sports Med. Auckl. NZ. 2008; 38:69-90.

40. Gerche AL, Roberts Timothy, Claessen G. The response of the pulmonary circulation and right ventricle to exercise: exercise-induced right ventricular dysfunction and structural remodeling in endurance athletes (2013 Grover Conference series). Pulm. Circ. 2014; 4:407-416. [PubMed: 25621154]

41. Pagourelias ED, Kouidi E, Efthimiadis GK, Deligiannis A, Geleris P, Vassilikos V. Right Atrial and Ventricular Adaptations to Training in Male Caucasian Athletes: An Echocardiographic Study. J. Am. Soc. Echocardiogr. 2013; 26:1344-1352. [PubMed: 23978677]

42. La Gerche A, Burns AT, D'Hooge J, MacIsaac AI, Heidbüchel H, Prior DL. Exercise Strain Rate Imaging Demonstrates Normal Right Ventricular Contractile Reserve and Clarifies Ambiguous Resting Measures in Endurance Athletes. J. Am. Soc. Echocardiogr. 2012; 25:253-262. e1. [PubMed: 22192334]

43. Kovacs R, Baggish AL. Cardiovascular adaptation in athletes. Trends Cardiovasc. Med. 2015 A recent review of physiologic vs. pathologic cardiac remodeling of the athlete's heart.

44. Pelliccia A, Maron BJ, Di Paolo FM, Biffi A, Quattrini FM, Pisicchio C, et al. Prevalence and Clinical Significance of Left Atrial Remodeling in Competitive Athletes. J. Am. Coll. Cardiol. 2005; 46:690-696. [PubMed: 16098437]

45. Rawlins J, Carre F, Kervio G, Papadakis M, Chandra N, Edwards C, et al. Ethnic Differences in Physiological Cardiac Adaptation to Intense Physical Exercise in Highly Trained Female Athletes. Circulation. 2010; 121:1078-1085. [PubMed: 20176985]

46. Pelliccia A, Maron BJ, Culasso F, Spataro A, Caselli G. Athlete's heart in women: Echocardiographic characterization of highly trained elite female athletes. JAMA. 1996; 276:211215. [PubMed: 8667565]

47. Basavarajaiah S, Boraita A, Whyte G, Wilson M, Carby L, Shah A, et al. Ethnic Differences in Left Ventricular Remodeling in Highly-Trained Athletes. J. Am. Coll. Cardiol. 2008; 51:22562262. [PubMed: 18534273]

48. La Gerche A, Burns AT, Mooney DJ, Inder WJ, Taylor AJ, Bogaert J, et al. Exercise-induced right ventricular dysfunction and structural remodelling in endurance athletes. Eur. Heart J. 2012; 33:998-1006. [PubMed: 22160404]

49. Wilson M, O’Hanlon R, Prasad S, Deighan A, MacMillan P, Oxborough D, et al. Diverse patterns of myocardial fibrosis in lifelong, veteran endurance athletes. J. Appl. Physiol. 2011; 110:16221626. [PubMed: 21330616]

50. Knackstedt C, Schmidt K, Syrocki L, Lang A, Bjarnason-Wehrens B, Hildebrandt U, et al. Longterm follow-up of former world-class swimmers: evaluation of cardiovascular function. Heart Vessels. 2015; 30:369-378. [PubMed: 24510255]

51. Pelliccia A, Maron BJ, Luca RD, Paolo FMD, Spataro A, Culasso F. Remodeling of Left Ventricular Hypertrophy in Elite Athletes After Long-Term Deconditioning. Circulation. 2002; 105:944-949. [PubMed: 11864923]

52. Maron BJ, Pelliccia A, Spataro A, Granata M. Reduction in left ventricular wall thickness after deconditioning in highly trained Olympic athletes. Br. Heart J. 1993; 69:125-128. [PubMed: 8435237]

53. Weiner RB, Wang F, Berkstresser B, Kim J, Wang TJ, Lewis GD, et al. Regression of "Gray Zone" Exercise-Induced Concentric Left Ventricular Hypertrophy During Prescribed Detraining. J. Am. Coll. Cardiol. 2012; 59:1992-1994. [PubMed: 22624842] 
54. Kokkinos PF, Narayan P, Colleran JA, Pittaras A, Notargiacomo A, Reda D, et al. Effects of Regular Exercise on Blood Pressure and Left Ventricular Hypertrophy in African-American Men with Severe Hypertension. N. Engl. J. Med. 1995; 333:1462-1467. [PubMed: 7477146]

55. Turner MJ, Spina RJ, Kohrt WM, Ehsani AA. Effect of Endurance Exercise Training on Left Ventricular Size and Remodeling in Older Adults With Hypertension. J. Gerontol. A. Biol. Sci. Med. Sci. 2000; 55:M245-M251. [PubMed: 10811155]

56. Hinderliter A, Sherwood A, Gullette ED, et al. Reduction of left ventricular hypertrophy after exercise and weight loss in overweight patients with mild hypertension. Arch. Intern. Med. 2002; 162:1333-1339. [PubMed: 12076231]

57. Boman K, Olofsson M, Dahlöf B, Gerdts E, Nieminen MS, Papademetriou V, et al. Left ventricular structure and function in sedentary and physically active subjects with left ventricular hypertrophy (the LIFE Study). Am. J. Cardiol. 2005; 95:280-283. [PubMed: 15642571]

58. Palatini P, Visentin P, Dorigatti F, Guarnieri C, Santonastaso M, Cozzio S, et al. Regular physical activity prevents development of left ventricular hypertrophy in hypertension. Eur. Heart J. 2009; 30:225-232. [PubMed: 19074443] Prospective study demonstrating lower risk of left ventricular hypertrophy in those who exercise compared to sedentary individuals with hypertension.

59. Pitsavos C, Chrysohoou C, Koutroumbi M, Aggeli C, Kourlaba G, Panagiotakos D, et al. The impact of moderate aerobic physical training on left ventricular mass, exercise capacity and blood pressure response during treadmill testing in borderline and mildly hypertensive males. Hell. J. Cardiol. HJC Hellēnikē Kardiologikē Epitheōrēsē. 2011; 52:6-14. Randomized-controlled trial demonstrating a significant decrease in left ventricular mass index in the exercise group.

60. Boman K, Gerdts E, Wachtell K, Dahlöf B, Nieminen MS, Olofsson M, et al. Exercise and cardiovascular outcomes in hypertensive patients in relation to structure and function of left ventricular hypertrophy: the LIFE study. Eur. J. Cardiovasc. Prev. Rehabil. 2009; 16:242-248. [PubMed: 19369828]

61. Baglivo HP, Fabregues G, Burrieza H, Esper RC, Talarico M, Esper RJ. Effect of moderate physical training on left ventricular mass in mild hypertensive persons. Hypertension. 1990; 15:I153. [PubMed: 2298471]

62. Reid CM, Dart AM, Dewar EM, Jennings GL. Interactions between the effects of exercise and weight loss on risk factors, cardiovascular haemodynamics and left ventricular structure in overweight subjects. J. Hypertens. 1994; 12:291-302. [PubMed: 8021483]

63. Guirado GN, Damatto RL, Matsubara BB, Roscani MG, Fusco DR, Seki MM, et al. Combined exercise training in asymptomatic elderly with controlled hypertension: Effects on functional capacity and cardiac diastolic function. Med. Sci. Monit. 2012; 18:CR461-CR465. [PubMed: 22739737]

64. Kelemen MH, Effron MB, Valenti SA, Stewart KJ. Exercise training combined with antihypertensive drug therapy: effects on lipids, blood pressure, and left ventricular mass. Jama. 1990; 263:2766-2771. [PubMed: 2332919]

65. Weeks KL, McMullen JR. The Athlete's Heart vs. the Failing Heart: Can Signaling Explain the Two Distinct Outcomes? Physiology. 2011; 26:97-105. [PubMed: 21487028] Overview of signaling mechanisms involved in physiologic and pathologic cardiac remodeling.

66. Ellison GM, Waring CD, Vicinanza C, Torella D. Physiological cardiac remodelling in response to endurance exercise training: cellular and molecular mechanisms. Heart. 2012; 98:5-10. [PubMed: 21880653] Review of signaling mechanisms involved in exercise-induced cardiac remodeling.

67. Mann N, Rosenzweig A. Can Exercise Teach Us How to Treat Heart Disease? Circulation. 2012; 126:2625-2635. [PubMed: 23184282] In-depth review of cellular and molecular mechanisms involved in the cardiac response to exercise.

68. Frystyk J. Exercise and the Growth Hormone-Insulin-Like Growth Factor Axis: Med. Sci. Sports Exerc. 2010; 42:58-66. [PubMed: 20010129]

69. McMullen JR, Shioi T, Huang W-Y, Zhang L, Tarnavski O, Bisping E, et al. The Insulin-like Growth Factor 1 Receptor Induces Physiological Heart Growth via the Phosphoinositide 3Kinase(p110a) Pathway. J. Biol. Chem. 2004; 279:4782-4793. [PubMed: 14597618] 
70. Yamashita K, Kajstura J, Discher DJ, Wasserlauf BJ, Bishopric NH, Anversa P, et al. ReperfusionActivated Akt Kinase Prevents Apoptosis in Transgenic Mouse Hearts Overexpressing InsulinLike Growth Factor-1. Circ. Res. 2001; 88:609-614. [PubMed: 11282895]

71. Serneri GGN, Boddi M, Modesti PA, Cecioni I, Coppo M, Padeletti L, et al. Increased Cardiac Sympathetic Activity and Insulin-Like Growth Factor-I Formation Are Associated With Physiological Hypertrophy in Athletes. Circ. Res. 2001; 89:977-982. [PubMed: 11717153]

72. DeBosch B, Treskov I, Lupu TS, Weinheimer C, Kovacs A, Courtois M, et al. Akt1 Is Required for Physiological Cardiac Growth. Circulation. 2006; 113:2097-2104. [PubMed: 16636172]

73. McMullen JR, Shioi T, Zhang L, Tarnavski O, Sherwood MC, Kang PM, et al. Phosphoinositide 3kinase (p110a) plays a critical role for the induction of physiological, but not pathological, cardiac hypertrophy. Proc. Natl. Acad. Sci. 2003; 100:12355-12360. [PubMed: 14507992]

74. McMullen JR, Amirahmadi F, Woodcock EA, Schinke-Braun M, Bouwman RD, Hewitt KA, et al. Protective effects of exercise and phosphoinositide 3-kinase(p110) signaling in dilated and hypertrophic cardiomyopathy. Proc. Natl. Acad. Sci. 2007; 104:612-617. [PubMed: 17202264]

75. Bernardo BC, Weeks KL, Pretorius L, McMullen JR. Molecular distinction between physiological and pathological cardiac hypertrophy: Experimental findings and therapeutic strategies. Pharmacol. Ther. 2010; 128:191-227. [PubMed: 20438756] In-depth review of the molecular and cellular mechanisms associated with physiologic and pathologic cardiac hypertrophy.

76. Akhter SA, Luttrell LM, Rockman HA, Iaccarino G, Lefkowitz RJ, Koch WJ. Targeting the Receptor-Gq Interface to Inhibit in Vivo Pressure Overload Myocardial Hypertrophy. Science. 1998; 280:574-577. [PubMed: 9554846]

77. Wettschureck N, Rütten H, Zywietz A, Gehring D, Wilkie TM, Chen J, et al. Absence of pressure overload induced myocardial hypertrophy after conditional inactivation of Gaq/Ga11 in cardiomyocytes. Nat. Med. 2001; 7:1236-1240. [PubMed: 11689889]

78. Garciarena CD, Pinilla OA, Nolly MB, Laguens RP, Escudero EM, Cingolani HE, et al. Endurance Training in the Spontaneously Hypertensive Rat Conversion of Pathological into Physiological Cardiac Hypertrophy. Hypertension. 2009; 53:708-714. [PubMed: 19221208]

79. Carneiro-Júnior MA, Pelúzio MCG, Silva CHO, Amorim PRS, Silva KA, Souza MO, et al. Exercise training and detraining modify the morphological and mechanical properties of single cardiac myocytes obtained from spontaneously hypertensive rats. Braz. J. Med. Biol. Res. 2010; 43:1042-1046. [PubMed: 21049244]

80. Kolwicz SC, MacDonnell SM, Renna BF, Reger PO, Seqqat R, Rafiq K, et al. Left ventricular remodeling with exercise in hypertension. AJP Heart Circ. Physiol. 2009; 297:H1361-H1368.

81. Kemi OJ, Wisløff U. Mechanisms of exercise-induced improvements in the contractile apparatus of the mammalian myocardium. Acta Physiol. 2010; 199:425-439.

82. Kemi OJ, Ceci M, Condorelli G, Smith GL, Wisloff U. Myocardial sarcoplasmic reticulum Ca2+ ATPase function is increased by aerobic interval training. Eur. J. Cardiovasc. Prev. Rehabil. 2008; 15:145-148. [PubMed: 18391639]

83. Collins HL. Daily exercise-induced cardioprotection is associated with changes in calcium regulatory proteins in hypertensive rats. AJP Heart Circ. Physiol. 2004; 288:H532-H540.

84. Bergmann O, Bhardwaj RD, Bernard S, Zdunek S, Barnabé-Heider F, Walsh S, et al. Evidence for Cardiomyocyte Renewal in Humans. Science. 2009; 324:98-102. [PubMed: 19342590]

85. Neves, VJ das. Exercise training in hypertension: Role of microRNAs. World J. Cardiol. 2014; 6:713. [PubMed: 25228951]

86. Wei X, Liu X, Rosenzweig A. What do we know about the cardiac benefits of exercise? Trends Cardiovasc. Med. 2014 Review of the clinical and molecular responses underlying the cardiovascular benefits of physical activity.

87. Liu X, Xiao J, Zhu H, Wei X, Platt C, Damilano F, et al. miR-222 Is Necessary for ExerciseInduced Cardiac Growth and Protects against Pathological Cardiac Remodeling. Cell Metab. 2015; 21:584-595. [PubMed: 25863248] 

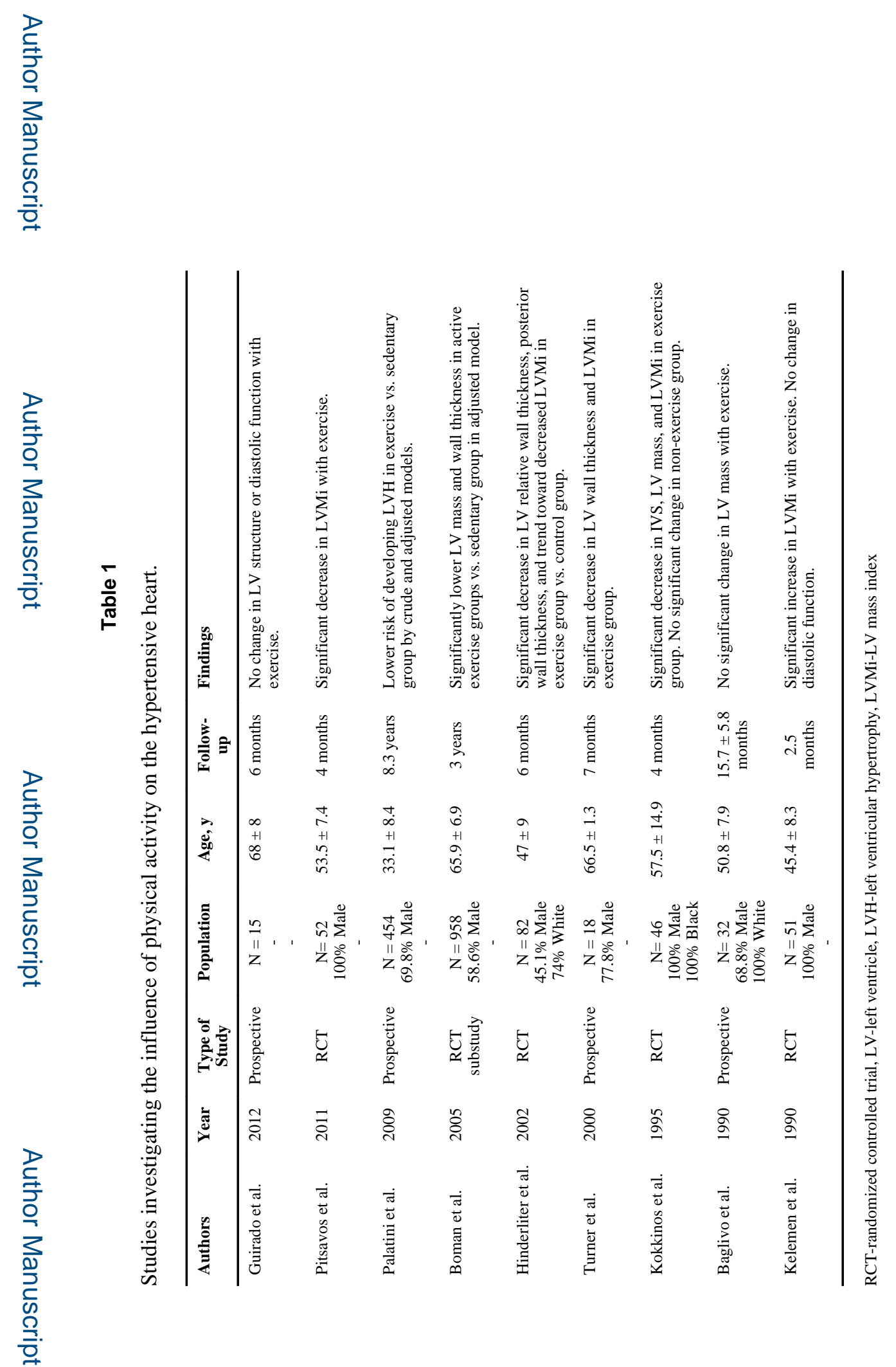

Curr Hypertens Rep. Author manuscript; available in PMC 2016 October 01. 